\title{
COSTUMbRes, RESISTENCIA Y PROTESTA ${ }^{1}$
}

\author{
por \\ Jost A. PIQUERAS ARENAS
}

Universitat Jaume I, Castelló.

Durante décadas los estudios de historia dedicados a la formación de la sociedad contemporanea han privilegiado el análisis del origen del capitalismo, las dificultades que hubo de vencer en el proceso de implantación y las consecuencias que acarreó a la sociedad en su conjunto y a los más desfavorecidos en particular.

Desde los tiempos de la Ilustración, el ascenso del capitalismo ha ido acompañado de la idea de progreso como representación de un estadio superior de civilización. La apologética del nuevo sistema ha insistido en ofrecer una visión optimista de las transformaciones y, a medio o largo plazo, de sus resultados. Gracias al incremento de la renta nacional los países industrializados acabarían alcanzando niveles de bienestar antes nunca conocidos, aunque en su marcha la máquina del progreso hubiera tenido que cobrarse algún tributo. El capitalismo vendría a significar una racionalización de los procesos productivos y de los mecanismos de asignación de recursos del modo más eficaz por medio del mercado; lo uno y lo otro no hubiera sido posible sin una modificación de las condiciones que regulaban la sociedad, por lo que la expansión del capitalismo debiera asociarse al progresivo reconocimiento de derechos y libertades individuales.

En el lado contrario, desde la perspectiva crítica con el proceso de implantación del capitalismo, aún admitiendo su inevitabilidad e incluso el avance que representaba respecto a la sociedad feudal, se suelen destacar los efectos de la proletarización en la población trabajadora y la desigualdad consustancial en la que se fundamentaba la nueva sociedad. La repercusión del capitalismo industrial en las condiciones materiales de existencia de la población trabajadora es un tema que permanece abierto desde que en 1835 Andrew Ure glosara las ventajas del sistema fabril para los obreros en relación a la indi-

1 E. P. THOMPson, Costumbres en común, Crítica, Barcelona, 1995, ISBN: 84-7423-628-2, 606 págs.

Hispania, LVL/3, núm. 194 (1996) 1133-1141 
gencia a que parecían condenados los artesanos manuales y, sobre todo, desde que diez años después Friedrich Engels publicó su indagación sobre las consecuencias devastadoras de la industrialización en la clase obrera inglesa. La discusión entre optimistas y pesimistas en torno a los efectos sociales de la revolución industrial se ha convertido en una controversia clásica dentro de la historia económica y social. No siempre ha sido fácil o deseable en esta discusión deslindar la materia de estudio de sus implicaciones ideológicas por cuanto las conclusiones permitían reforzar en sentido contrario la valoración histórica (y política) de la implantación del capitalismo.

Abundantes trabajos sobre el tema se han dedicado a cuantificar cambios y niveles de vida y en menor medida a ponderar aquello que resultaba más difícil medir: la calidad de vida, la felicidad o la autosatisfacción de la comunidad que experimentó las transformaciones.

En Costumbres en comun, Edward Thompson avanza unos pasos en estas últimas direcciones. De un lado, después de habernos mostrado en una obra anterior La formación de la clase obrera en Inglaterra entre 1780 y $1832^{2}$, nos traslada al momento previo del siglo xviII, en el que pugnaban las realidades capitalistas con unas formas tradicionales en trance de desaparecer. En segundo lugar, Thompson se distancia de la identificación entre capitalismo y la idea de progreso en la medida en que aquél encierra explotación y aniquilamiento de valores humanos que merecen ser recuperados como experiencia histórica y, en algunos casos, como referencia de futuro. De manera deliberada Thompson deja traslucir en la investigación el móvil que le guía y la implicación personal a favor de los sectores populares a los que dedica el estudio y en cuya protesta y resistencia fundamenta su propia defensa y la no menos apasionada protesta.

Costumbres en contín reúne siete estudios precedidos de una clarificadora introducción sobre costumbre y cultura en la que adelanta las claves interpretativas del trabajo ${ }^{3}$. En los textos, elaborados a lo largo de casi treinta años, subyace un mismo argumento: la costumbre, expresión de la cultura plebeya, aparece destinada a preservar la economía tradicional y los usos sociales y morales populares. La costumbre habría permitido resistir el proceso de expansión capitalista, percibido bajo la forma de explotación o de alteración violenta de las pautas de trabajo y de ocio. Un mismo argumento que será desarrollado mediante argumentaciones distintas según las aproximaciones temáticas efectuadas en diferentes momentos. Un proceso de gestación tan dilatado permite apreciar las matizaciones introducidas por el autor en su esquema en el curso de los años.

2 E. P. THOMPSON, La formación de la clase obrera en Inglaterra, Critica, Barcelona, 1989, en el que dedicaba un capitulo («Niveles y experiencias») a analizar las condiciones de vida durante la revolución industrial.

3 Dos de los estudios son de sobra conocidos del público español («La economia "moral" de la multitud en la Inglaterra del siglo xvil» y «Tíempo, disciplina de trabajo y capitalismo industrial») por haber sido incluidos en una anterior recopilación, E. P. THOMPSON, Tradición, revuelta y consciencia de clase. Estudios sobre la crisis de la sociedad preindustrial, Critica, Barcelona, 1979.

Hispania. LVI/3, nủm. 194 (1996) 1133-1141 
En el primero de los textos, "Patricios y plebeyos», se interesa por las relaciones entre sectores sociales en una época de capitalismo agrario y comercial previa a la industrialización. Sostiene que el sistema patriarcal vigente anulaba la conflictividad de clase en tanto los sectores populares carecían de verdadera conciencia social, en la medida en que las adhesiones y fracturas sociales eran verticales y estaban definidas por el oficio. De ahí su afirmación de hallarnos ante una sociedad de una sola clase, la gentry, manifestación del capitalismo depredador; enfrente estaría la gente pobre, el término con el que la primera designaba a la población subordinada.

En esa sociedad sin clases, pero en la que era real la dualidad gobernantes/gobernados y el antagonismo social en el que se evidencian "fragmentos del protoconflicto", se contraponen patricios y plebeyos, dos campos de atracción ante los que todos los sectores intermedios quedan rendidos por relaciones clientelares. Por plebeyos debe entenderse una multitud que aunque con dificultad llegue a presentarse políticamente, carece de estructura y conciencia de clase.

En el sistema paternalista establecido, nos dice el autor, la gentry ejerce el control mediante la hegemonía cultural y asigna a la multitud un papel subalterno, que en ocasiones la plebe subvierte con la protesta como instrumento con el que negociar los límites de su actuación independiente. Sin embargo, lo habitual sería el predominio de una actitud deferente que da lugar a un sistema de consenso basado en la recíproca aceptación social.

La situación de equilibrio consensuado se vio alterada en el curso del siglo XVIII, cuando las reformas orientadas a implantar la lógica de la economía de mercado entraron en conflicto con la economía moral de la plebe. En tal circunstancia, los plebeyos recurrieron a la costumbre para resistir la presión y salvaguardar sus usos y derechos. Pero la costumbre, nos dice, no era exactamente la tradición sino en muchos casos respondía a recientes inventos con los que se reivindicaba nuevos derechos y se procuraba poner freno a las pretensiones del adversario. La costumbre, en ese sentido, suponía una forma de retórica de legitimación y a la vez era un campo de contienda. Descansaba en normas y usos consuetudinarios, pero también en formas más opacas a la vigilancia de las clases altas a través de un tipo de cultura popular con códigos propios de comportamiento cada vez más distantes de las pautas establecidas por la clase dominante.

El panorama descrito arroja algunas dudas en torno a la argumentación del autor. En particular en la esfera de la gestación de una cultura autónoma popular cuando supuestamente la gentry ejercía su dominación valiéndose según se nos dice- de la hegemonía cultural con preferencia al poder económico o físico (pág. 58). De otra parte, no deja de sorprender la presentación de una sociedad basada en el equilibrio, el consenso social y el dominio mediante fórmulas hegemónicas en el siglo en el que se crean las deportaciones a Australia -en donde los presos serán cedidos como siervos escriturados-y en el que se crean cien nuevos delitos castigados con la pena capital, según el propio Thompson nos recuerda (pág. 64). La coerción directa no puede reducirse a la disciplinación de la fuerza de trabajo en vísperas de la 
promulgación de las leyes de cercamientos y de pobres. En tercer lugar, el conglomerado sin identidad de clase reunido en la expresión plebe o en la voz pobre no mejora la ambivalencia de los términos clases populares, campesinado o clases bajas urbanas. La pobreza, en cualquier caso, es una condición, no una categoría social que pueda oponerse antagónicamente a una clase como la gentry a la que se reconocen todos los atributos, pues hay pobres sin trabajo y hay propietarios pobres. Del mismo modo, parecen darse plebeyos que controlan la corporación y plebeyos asalariados, criados o campesinos libres. Podemos comprender lo que les une, ¿podríamos conocer lo que les separa cuando disputan sus medios de subsistencia?

A una peculiar manifestación de la cultura política de la plebe dedica Thompson un estudio ampliamente difundido que supuso acunar un concepto histórico hoy prácticamente universal: "La economía "moral" de la multitud en la Inglaterra del siglo XVII». Con él salía al paso a las visiones espasmódicas de las protestas sociales en la sociedad preindustrial y, en concreto, de los motines de subsistencia. El autor se pregunta por la motivación, conducta y función de los motines y considera que responden a una acción directa y disciplinada de las masas; una protesta destinada a defender derechos o costumbres tradicionales agredidos por prácticas incorrectas de comerciantes que ocasionaban alzas de precios y hambre en una economía de subsistencia. Estos atropellos incidían en el consenso popular acerca de qué era legítimo o ilegítimo y alteraba la visión de las normas y obligaciones sociales y de las funciones económicas reconocidas a cada sector social, es decir, de aquello que constituía su economía moral: una mentalidad, unas expectativas, unas tradiciones adaptadas a las necesidades de la comunidad. La movilización de la multitud obedecería a un modelo de comportamiento complejo en el que la población amotinada recurre a la defensa del modelo paternalista establecido para obligar a las autoridades a ser consecuentes con el respeto a las reglas instituidas. El motín se convierte entonces en un instrumento con el que negociar el restablecimiento de las condiciones irregularmente alteradas.

"La economía moral revisada" da cuenta del impacto del anterior texto y permite al autor precisar el concepto de economía moral, con lo que sale al paso de algunas lecturas críticas. Son precisiones muy oportunas para el lector español teniendo en cuenta el uso inmoderado que la historiografía más ávida de novedades ha hecho de esa noción en los últimos lustros. Thompson nos recuerda que nunca pretendio ofrecer un modelo de comportamiento de todas las protestas sociales de la época preindustrial, o que en su "multitud" pudieran ser incluidas todas las clases de multitud: "Las conclusiones... no pueden aplicarse directamente a cualquier "mercado campesino" ni a todos los mercados protoindustriales", nos recuerda. Será preciso tener en cuenta el contexto histórico y económico en que se sitúan tales acciones, lo que en su caso le obligó a reconstruír el mercado y las prácticas comerciales según el modelo paternalista establecido en la Inglaterra del siglo xvir. Su noción estaba referida a los enfrentamientos en el mercado por el derecho a los alimentos esenciales, en situaciones de emergencia, ante la actuación especula-

Hixpania, LVI3, núm. 194 (1996) 1133-1141 
tiva de los comerciantes. Cualquier extrapolación que se pretenda -añadimos nosotros-- supondrá identificar nuestro caso con una economía en pleno proceso de transformación, una vez la revolución del siglo anterior habra socavado las bases del ordenamiento feudal y el capitalismo iba ganando la agricultura y, con ella, el conjunto del mundo rural y urbano en el que se sitúa el abastecimiento y el mercado. Quien lea Thompson debiera leer también su observación acerca de la contextualización antes de trasladar mecánicamente el método de análisis.

Al contexto de la industrialización pertenece «Tiempo, disciplina de trabajo y capitalismo industrial». En el se observa la reestructuración de los hábitos laborales y, en el sentido más específico, los cambios en la representación interna del tiempo a partir de la modificación de los ciclos de trabajo. En la sociedad protoindustrial (Thompson rechaza hablar de preindustrial porque sería desconocer las actividades manufactureras previas a la mecanización) la dedicación al trabajo artesanal no podía sujetarse a normas regulares debido a la ausencia de total sincronización entre las fases del proceso productivo y a la simultaneidad de tareas desempeñadas por los artesanos. EI campesino o el artesano independiente medía su tiempo de trabajo en el «quehacer» y no dudaba en festejar a "San Lunes" si ese era su deseo, el día dedicado al mercado y a sus asuntos. La sociedad industrial obligó a regular el trabajo asalariado mediante el recurso a la disciplina, la educación (como aprendizaje de laboriosidad y disciplina horaria) y los incentivos materiales. Thompson estudia las resistencias a ese cambio desde una doble perspectiva: el sentido sociológico del tiempo y la medida del tiempo como explotación laboral. Los trabajadores debieron luchar contra las horas de trabajo y sobre las horas de trabajo, ya que los patronos, gracias al reloj, parecen dueños del tiempo que mide las actividades. La aparición de la sociedad industrial supuso la administración del tiempo, convertido en mercancía, y la rígida división entre el trabajo y la vida.

Al sistema de normas y sanciones que autorregulan la comunidad van dedicados los dos últimos estudios. En ambos la perspectiva antropológica se adueña del análisis y la enumeración de casos y situaciones no consigue trascender empiricamente la simplicidad de las ideas contempladas. "La venta de esposas» ilustra una práctica plebeya que, según parece, tuvo cierta difusión a finales del XVIII y comienzos del XIX. La inexistencia del divorcio y las normas comunitarias defensoras del matrimonio y de la unidad doméstica familiar (entendida también como unidad económica) forzaron un ritual mediante el que una vez cumplidas determinadas formalidades públicas, se consumaba la separación. Thompson lo interpreta como un divorcio ritual de pobres. En este caso, el ejemplo de autorregulación no podía ser más desafortunado, por más que el autor quiera salir al paso de las críticas recibidas desde sectores feministas.

"La cencerrada" alude a los rituales burlescos contra los transgresores de ciertas normas de la comunidad cuando una parte de la ley todavía estaba en manos de ésta. Debe entenderse como una forma de autocontrol con el que se sancionan faltas antisociales. El problema es que muchas de estas faltas esta- 
ban sujetas a los prejuicios de la población. También aquí la defensa de la ley propia ante una ley distanciada resulta contradictoria, ya que la cencerrada se nos muestra como una modalidad de coerción comunitaria sobre conductas personales reprobadas con frecuencia sin fundamento objetivo, caso de las sátiras dirigidas al matrimonio de las viudas. Sospecho que esta observación no será obstáculo para que en unos años contemos entre nosotros con un amplio repertorio de cencerradas ibéricas, máxime cuando siguen vigentes en numerosos lugares de nuestra geografía.

Hemos dejado para el final el capítulo que en mi opinión ofrece mayor interés y quizá sea uno de los textos más valiosos escritos desde la historia social sobre historia agraria. Por sí solo justifica el interés del libro y lo convierte en una de obra fundamental, si se nos admite este tipo de solemnidades.

"Costumbre, ley y derecho natural" constituye un largo estudio de un centenar de páginas sobre la disputa de los comunales. Si en Whigs and Hunters abordaba el origen de las Black Acts en las incursiones de los cazadores furtivos en los bosques reales ${ }^{4}$, la cuestión de la definición de usos derechos comunitarios o exclusivos es ahora presentada desde la perspectiva opuesta. Las comunidades se sirvieron de la costumbre, en los términos antes acotados, para preservar en el siglo xvIII las tierras comunales. La costumbre adquiere fuerza de ley y se concreta en la práctica tanto en la defensa de usos agrarios como en la disputa de nuevos límites. Del mismo modo que los usos comunales eran locales, así sería igualmente local la costumbre destinada a regularlos y protegerlos.

El estudio nos sitúa en una época del xviI en que los campesinos todavía no han sido expulsados de todas partes y subsisten formas no absolutas de tenencia. El crecimiento demográfico e industrial potenció la existencia de empleos secundarios en los que los beneficios marginales adquirieron cada vez más importancia en la economía de subsistencia de los pobres. El conflicto será inevitable cuando converjan derechos de usufructo en campesinos y propietarios.

En Whigs and Hunters el Derecho se presentaba no sólo -ni principalmente- como instrumento de poder de la clase dominante, sino como límite a la actuación de esta clase y ante todo como un escenario de lucha y conflicto en el que se definen los derechos de las partes litigantes. En "Costumbre, ley y derecho naturaln, la costumbre, ley y praxis a un tiempo, desempeña ese mismo papel: «la costumbre también puede verse como escenario del conflicto de clases, en el área de fricción situada entre la práctica agraria y el poder políticon, afirma (pág. 131). Las condiciones específicas del Setecientos y la presión de la economía capitalista en la agricultura generó esá fricción entre propietarios y commoners. Mientras, los tribunales dictaminaban la propiedad particular en favor de los señores pero no podían dejar de reconocer el límite establecido en esas propiedades por los usos basados en la costumbre.

La lógica capitalista fundada en derechos excluyentes de uso se vio retrasada en aquellos términos en que se mantenía el sisterna de copyhold $\mathrm{u}$ otras formas

4 E. P. THOMPson, Whigs and Hunters, Penguin Books, Hardmondswoth, 1977. 
de tenencia consuetudinaria, aunque los cercamientos reforzaron el derecho del propietario. Los cercamientos, sin embargo, hicieron inevitable el conflicto de clase. Pero Thompson no termina de aclarar en este punto la naturaleza del conflicto... ni de las clases que lo protagonizan en una sociedad «de una sola clase». Sin duda este es el principal problema no resuelto del autor.

La obra se resiste a precisar el grado de diferenciación social que recorre la sociedad bajo la fórmula ambigua de plebeyos. Mientras se refiere al ámbito genérico de la cultura, de los motines populares, los hábitos de trabajo, conductas familiares y sanciones hacia los transgresores de la norma comunitaria, el término plebeyo puede funcionar como análogo al concepto gramsciano de clases subalternas, en el que parece inspirarse. Ahora bien, al trasladar la cuestión de la costumbre al uso de la tierra a la defensa de ese derecho, nos aparecen por vez primera y con total claridad un conjunto de relaciones sociales que resulta imposible eludir. Tanto es así que Thompson rompe aquí con la terminología que se ha impuesto y afirma: «A decir verdad, los "pobres" era una expresión acuñada por la gentry que a veces podía ocultar un vigoroso campesinadon (pág. 206). De modo que la lucha adquiere perfiles más nítidos, entre campesinos y propietarios. Y la apelación a la costumbre, así como la misma "construcción" de la costumbre, reviste toda su importancia en un contexto determinado.

El texto de Thompson se enriquece precisamente por el grado de concreción que adquiere el tema tratado cuando desciende al terreno de la subsistencia y de las relaciones de producción. Los matices ganan importancia porque permiten explicar la disputa en el seno de la misma comunidad, por ejemplo, entre partidarios del cercamiento por mutuo acuerdo y partidarios de la economía consuetudinaria. Aunque el autor no insista en esa dirección, eso será posible gracias a que la pluralidad de situaciones entre usufructuarios, con intereses progresivamente divergentes, debio favorecer la disgregación de los usos.

Lamentablemente la traducción no ha tenido en cuenta en todos los casos la diversidad de formas de tenencia de la tierra. Así, el copyhold queda reducido a una tenencia basada en usos consuetudinarios similar a un arrendamiento particular, cuando se trata de una figura equiparable a la enfiteusis. Los arrendamientos corren peor suerte, pues si en nota de revisión se nos informa de que el rackrent corresponde a un arrendamiento no tradicional, esto es, contractual, el leasehold se cita como un arrendamiento más, que, en el contexto, ha de entenderse regulado asimismo por el derecho consuetudinario. Thompson destaca la importancia de los copyholders como freno a las pretensiones capitalistas, lo que adquiere sentido describiendo el contenido de esa relación consuetudinaria en la que la división de dominios otorga al enfiteuta el uso de la tierra por tiempo indefinido. Después de todo, el problema no sería muy distinto en la España del siglo XIX.

La obra de E. P. Thompson que comentamos, por la novedad de sus enfoques y la riqueza de sus sugerencias, ofrece una explicación de los comporta- 
mientos sociales del Setecientos inglés equiparable a lo que pudo suponer $\mathrm{La}$ formación de la clase obrera en Inglaterra para los estudios sobre la constitución de las clases sociales. Sin embargo, la aportación no deja de ser fragmentaria desde el momento en que se confía a la cultura la función de desentrañar la vida social. Porque una cosa sería reconocer que a través de la costumbre podamos reconstruir determinadas actitudes colectivas -defensa, resistencia y reivindicación de la forma de existencia- y otra muy distinta es que ese nivel de análisis permita iluminar las causas del conflicto o la estructura social en que éste se genera.

Para Thompson las economías contrapuestas, la orientada por el mercado y la regida por la moral de la multitud, no sólo resultan distintas sino que se explican con parámetros singulares. La economía capitalista implicará conflictos de clases porque podremos reconocer relaciones sociales y experiencias perfectamente delimitadas. En cambio en la sociedad tradicional las fuerzas sociales están en una suerte de equilibrio homeostático, con ajustes periódicos, basada en el consenso. La perturbación del orden establecido desencadena la movilización de recursos entre los que la costumbre desempeña un papel cohesionador. Cuando Thompson describe esa sociedad tradicional únicamente emplea términos económicos para referirse a la introducción de la agricultura capitalista, mientras omite caracterizar la economía tradicional dejándola en su regulación consuetudinaria; nunca informa sobre el marco social en que se desenvuelve. En suma, hay una abstracción de las relaciones sociales en que se desenvuelve la plebe: sabemos que no son jornaleros y que oponen su independencia a la expansión de la propiedad capitalista. Pero a la altura inglesa de 1760, ¿no producen sus excedentes también para un mercado capitalista?

Quizá la cuestión resida en reconocer que esa economía llamada tradicional encierra una tradición feudalizante en trance de ser barrida por la expansión capitalista y su moderno concepto de propiedad. Sin miedo a las palabras. La protesta comunalista estaría protagonizada por el último sector independiente de la población agraria y por aquéllos que se aferraban a formas de tenencia de la tierra y a usos comunales que aunque originados en el feudalismo, les permitían mantener en sus manos los medios precisos de subsistencia. De no dar este paso, y Thompson no llega a darlo, estaremos ante una historia de actitudes colectivas (de la multitud, mediante una cultura), prescindiendo de las actividades colectivas.

Podemos especular sobre la inevitabilidad del proceso y rescatar las luchas que trataron de frenarlo siempre y cuando no perdamos de vista que resultó inexorable e irreversible. Del mismo modo que los poderosos yeomanry del xVII habian entrado en declive y a finales del xVIII los freeholders tenían en sus manos menos del veinte por ciento de las tierras, la disolución de los vínculos consuetudinarios, el cercamiento de comunales y la confirmación de usos exclusivos del suelo intensificó el empobrecimiento y la proletarización de la población agraria.

Costumbres en común explicita la agenda política de Thompson como pocas obras anteriores. Nos invita a recordar la naturaleza humana precapi-

Hispania, LV/3, núm. 194 (1996) 1133-1141 
talista, vigente antes que la revolución industrial modificase las necesidades. $\mathrm{Y}$ lo hace porque tal vez ese conocimiento nos prepare para nuevas expectativas. Recupera rasgos esenciales de la cultura plebeya como la solidaridad y la resistencia a la explotación. Nos presenta una economía moral que implica una noción casi natural de bien público y de autorregulación colectiva frente a la autoridad y a los comportamientos que infringen el derecho común. Nos previene contra la inevitabilidad del cambio tecnológico que destruye valores y acrecienta la explotación. Y traslada estas consecuencias a los países en vías de industrialización al tiempo que considera válida sus reflexiones para los más industrializados. El pasado, viene a decirnos, nos devuelve modos de experiencia olvidados, nos invita a reaprender algunas artes de vivir perdidas con la revolución industrial y nos enseña una cultura de la resistencia sin duda útil para nuestros días.

La incompatibilidad entre la lógica del desarrollo del capitalismo industrial y el desarrollo humano reafirma al Thompson antiindustrialista y al portavoz de un humanismo social. Desde un punto radicalmente distinto al de Laslett, también Thompson mira con nostalgia el «mundo que hemos perdidon, una feliz e improbable arcadia en la que la humanidad pasaba penurias pero era dueña de su destino personal. 